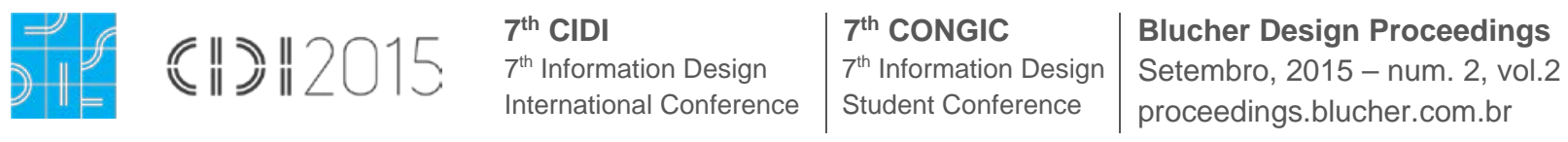

\title{
Apontamentos sobre o design gráfico moderno argentino: as revistas nueva visión e Summa ${ }^{1}$ Notes on the Argentine modern graphic design: the magazines nueva visión and Summa
}

\author{
Patricia Amorim, Virginia Cavalcanti
}

revista, nueva visión, summa, argentina

O propósito deste artigo é traçar um breve perfil das publicações argentinas nueva visión (1951-1957) e Summa (1963-1969), as quais exerceram papel importante na divulgação e no debate das inovações lançadas pela arte concreta, pelo desenho industrial e pela arquitetura moderna na Argentina nas décadas de 1950 e 1960. Partindo de uma abordagem histórica, busca-se aqui enunciar as condições que levaram ao surgimento desses periódicos, bem como enfatizar suas características gráficas como reflexo de seu interesse no tema desenho industrial e de sua afinidade estética com os referenciais da arte concreta (nueva visión) e do design suíço (Summa).

magazine, nueva visión, summa, argentina

The purpose of this article is to outline a brief profile of Argentine publications nueva visión (1951-1957) and Summa (1963-1969), which played an important role in the dissemination and discussion of the concrete art, the industrial design and the modern architecture in Argentina over the 1950s and 1960s. From a historical approach, we seek to set out the conditions that led to the emergence of these journals, as well as take into consideration their graphic characteristics related to the concrete art (nueva visión) and the Swiss style (Summa).

\section{Introdução}

A emergência do desenho industrial na Argentina iniciada nos anos 1950 relaciona-se com uma intensa etapa de industrialização e modernização cultural então vivenciada por aquele país. Esse processo foi acompanhado de perto por alguns periódicos, os quais, vinculados ao campo das artes ou da arquitetura, fizeram uso de seu discurso e de sua forma gráfica para expressar, divulgar e debater as inovações propostas pela arte concreta, pelo desenho industrial e pela arquitetura moderna.

Nesse cenário editorial, nueva visión foi uma das primeiras publicações a refletir as expectativas a respeito do desenho industrial naquele país. Essa revista, criada em 1951 pelo artista Tomás Maldonado em parceria com o pintor Alfredo Hlito e o então estudante de

1 Este artigo resulta da tese de doutorado Cruzadas editoriais no Brasil e na Argentina: o desenho industrial na perspectiva das revistas Habitat e Mirante das Artes,\&tc, nueva visión e Summa [1950-1969], de autoria de Patricia Amorim, desenvolvida no Programa de Pós-Graduação em Design da Universidade Federal de Pernambuco (UFPE), sob orientação da professora Virginia Cavalcanti e defendida em fevereiro de 2015.

P. Amorim, V. Cavalcanti. 2015. Apontamentos sobre o design gráfico argentino: as revistas nueva visión e Summa. In: C. G. Spinillo; L. M. Fadel; V. T. Souto; T. B. P. Silva \& R. J. Camara (Eds). Anais [Oral] do $7^{\circ}$ Congresso Internacional de Design da Informação/Proceedings [Oral] of the 7th Information Design International Conference | CIDI 2015 [Blucher Design Proceedings, num.2, vol.2]. São Paulo: Blucher, 2015. ISSN 2318-6968, ISBN: 978-85-8039-122-0. DOI 10.5151/designpro-CIDI2015-cidi_157 
arquitetura Carlos Méndez Mosquera, ganhou vida a reboque da efervescente cena vanguardista portenha, então animada pela arte concreta.

Já em 1963, apareceu Summa. Méndez Mosquera, que àquela altura dividia-se entre a condução da agência de publicidade Cícero, a editora especializada Infinito e a atividade como docente universitário, lançou a revista junto a um grupo do qual também fazia parte sua esposa, a arquiteta Lala Méndez Mosquera. A partir de 1966, Lala passou a dirigir a publicação, cujo interesse na crônica da arquitetura argentina e latino-americana também abarcou uma relevante cobertura sobre o "diseño industrial" naquele país. Salienta-se ainda que, em pouco tempo, antigos membros de nueva visión também integraram esta redação.

Assim, partindo de uma abordagem histórica, este artigo pretende traçar um breve perfil dessas duas publicações argentinas, buscando enfatizar os aspectos relacionados às suas características visuais como reflexo de seu interesse no tema do desenho industrial e de sua afinidade estética com os referenciais da arte concreta (nueva visión) e do design suíço (Summa).

\section{Tomás Maldonado e a vanguarda concretista na Argentina}

Nas primeiras décadas do século XX, o campo da pintura na Argentina foi influenciado por ideias vanguardistas introduzidas por imigrantes, fossem eles residentes ou estivessem apenas de passagem. Manifestações como o grupo Madi ou o movimento Perceptismo são alguns dos exemplos de reuniões de artistas argentinos e estrangeiros que exploraram os conceitos da abstração e da arte concreta vindos da Europa. Foi nesse circuito que também transitou Tomás Maldonado, figura central na divulgação do concretismo na Argentina e, posteriormente, do desenho industrial, o qual, em 1951, fundou a revista nueva visión.

Aluno da Academia Nacional de Arte de Buenos Aires no final dos anos 1930 - período político conturbado no país e que ficou conhecido como a Década Infame -, Maldonado logo aproximou-se das ideias vanguardistas no campo da pintura. Em 1941, aos 19 anos, junto aos colegas Alfredo Hlito, Claudio Girola e Jorge Brito, assinou o primeiro de seus escritos polêmicos, movido pelas inquietações do grupo em favor de uma renovação nas artes visuais, o beligerante Manifiesto de cuatro jóvenes.

Em 1944, é publicado o único número da revista Arturo. De acordo com Perazzo (1997), para ali foram canalizadas energias criativas de jovens ávidos por novidades, contribuindo para a afirmação da não-figuração construtiva no país. Em colaboração com esse expressivo e vibrante conjunto de poetas e artistas, Maldonado projetou a capa da publicação, inspirada na abstração expressionista, e a pintora Lidy Prati, sua então esposa, foi autora das vinhetas das páginas internas, na linha concreta.
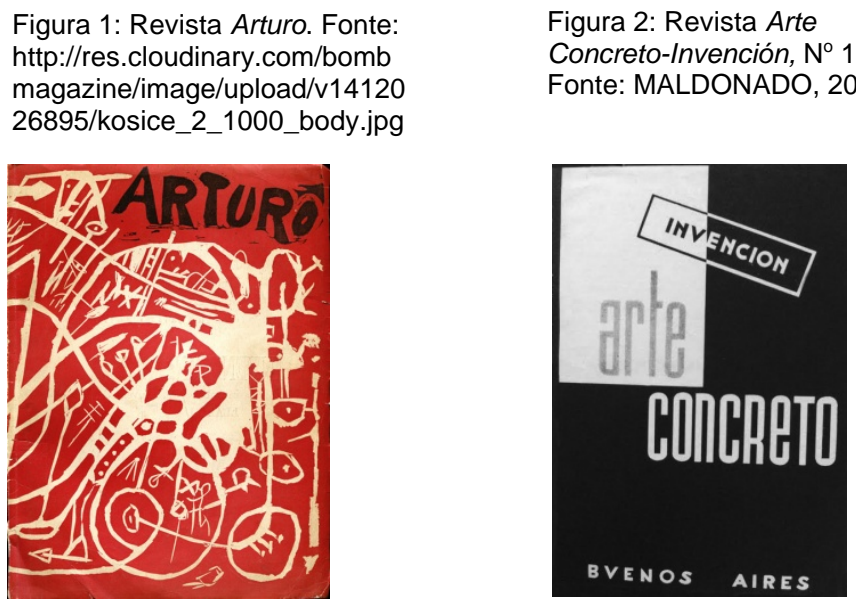

Anais [Oral] do $7^{\circ}$ Congresso Internacional de Design da Informação | CIDI 2015

Proceedings [Oral] of the 7th Information Design International Conference | IDIC 2015 
Em 1945, os grupos vanguardistas organizaram exposições importantes em Buenos Aires e nesse mesmo ano foi fundada a Asociación Arte Concreto-Invención (AACI), que contou com a adesão de um grande número de artistas. Além de promover mostras, a Asociación publicou uma revista homônima em agosto e em dezembro de 1946. Segundo Perazzo (1997), eram repletas de artigos apaixonados e violentos, como forma de divulgar as ideias desses artistas. No segundo número da publicação, foi reproduzido o Manifesto Invencionista, onde estavam delineadas as ideias fundamentais da AACl: a ruptura com a figuração e a afirmação dos valores do concretismo.

De acordo com Perazzo (1997), a arte concreta, na visão dos invencionistas, seria a superação dialética da arte abstrata, pois ao contrário de abstrair ela inventaria novas realidades.

O ano de 1948 foi decisivo para as atividades da Asociación Arte Concreto-Invención, principalmente por conta da exposição Nuevas Realidades, sediada na galeria Van Riel, onde reuniram-se artistas de todas as orientações dentro da não-figuração e onde também foram expostas fotografias de exemplares da arquitetura moderna italiana. Fez parte desse grupo, por exemplo, o arquiteto milanês Ernesto Rogers, que nesta ocasião proferiu a conferência Ubicación del arte concreto (Lugar da arte concreta) (DEAMBROSIS, 2011). Na Itália, Rogers havia trabalhado na revista Quadrante, com Pietro Maria Bardi, e editado a revista Domus entre 1946 e 1947. Acredita-se que foi através dele que Maldonado estabeleceu contato com Max Bill, o que culminou em sua primeira viagem à Europa ainda em 1948. Jornada que foi acompanhada com entusiasmo, mesmo que à distância, pelos jovens artistas e arquitetos que então o rodeavam em Buenos Aires.

Circulando pela Itália, Suíça, França e Alemanha, Maldonado também conheceu pessoalmente Henry van de Velde, Bruno Munari, Gillo Dorfles, Max Huber, Georges Vantongerloo, Richard P. Lhose, Friedel Vordemberge-Gildewart. Esses importantes arquitetos, designers e artistas concretos iriam, no conjunto dessa experiência, renovar o entendimento de Maldonado sobre o ato artístico, levando-o a um interesse cada vez maior pela ampliação do espaço da forma a outros territórios além da pintura. Tal desejo de fundir as artes a um todo maior implicou em manter-se em contato com a arquitetura, o urbanismo, o desenho industrial e a tipografia.

Em seu retorno à Argentina, Maldonado assumiu a diagramação da revista Ciclo, dedicada à arte, literatura e pensamento modernos. As duas únicas edições foram publicadas em 1948 e 1949 e marcaram a transição de Maldonado para o campo da arquitetura e da comunicação visual. O segundo número da revista, por sinal, foi o que apresentou maiores inovações gráficas, dentre elas o emprego da fonte sem serifa por ele trazida da Europa, como detalha Carlos Méndez Mosquera:

Os tipos eram uma família de fontes - el etrusco [sem serifa] - enraizada nas características mais puras da groteske suíço-alemã, inexistente no país, e que depois tiveram de ser completados com importação direta da Nebiolo [fundidora de tipos italiana] (MÉNDEZ MOSQUERA, 1969: 86).

Figura 3: Revista Ciclo. Fonte: MALDONADO, 1997.

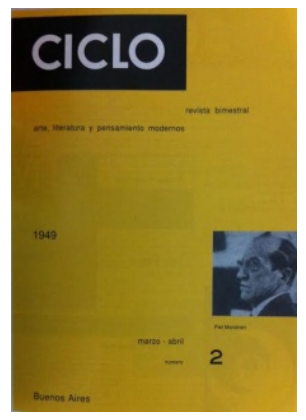

Figura 4: Revista Cea 2. Fonte: MALDONADO, 1997

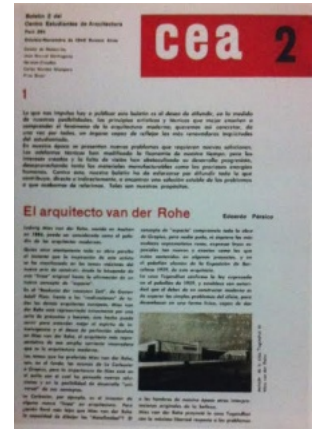

Anais [Oral] do $7^{\circ}$ Congresso Internacional de Design da Informação | CIDI 2015 
A composição tipográfica, concebida por Maldonado e Hlito, era disposta na página de forma rigorosa e controlada, incorporando ao plano gráfico os princípios modernos de universalidade, síntese e legibilidade (DEVALLE, 2006). Credita-se ainda a essa edição de Ciclo a primeira tradução para o espanhol de textos de Moholy-Nagy, André Breton, Piet Mondrian e Max Bill (MÉNDEZ MOSQUERA, 1997).

Em 1949, Maldonado participaria da diagramação e elaboração de textos para o número 2 do Boletín del Centro de Estudiantes de Arquitectura, Cea 2, cujo comitê de redação era formado por Juan Manuel Borthagaray, Gerardo Clusellas, Carlos Méndez Mosquera e Pino Sivori. Lançado em outubro, o impresso difundiria o escrito Diseño Industrial e Sociedad, de autoria de Maldonado e considerado o primeiro artigo sobre desenho industrial publicado na Argentina.

[...] O desenho industrial parte do princípio de que todas as formas criadas pelo homem têm a mesma dignidade. $O$ fato de uma forma ser destinada a desempenhar uma função mais especificamente artística do que outras não invalida a certeza desse princípio. Na verdade, uma pintura tem uma função distinta da de uma colher, mas a forma da colher é também um fenômeno da cultura.

[...] Tal como imaginamos, o artista do futuro deve olhar para novos horizontes de criação, entrando no mundo da produção em série de objetos, objetos de uso cotidiano e popular, que, em última análise, constituem a realidade mais imediata do homem moderno. (MALDONADO, 1997: 64-5).

Nesse momento, portanto, os problemas relacionados ao universo pictórico começam a ceder espaço a novos temas que se tornariam centrais da atuação de Maldonado enquanto artista concreto, designer e educador, como ele mesmo explica:

Este é um texto importante no meu desenvolvimento, porque nele se encontra, de forma embrionária, um argumento que vai dominar todo o meu itinerário teórico posterior: o papel que o desenho industrial, juntamente com a arquitetura e urbanismo, deve assumir como fator de requalificação do nosso meio ambiente. É precisamente para apoiar esta ideia que, com um grupo de amigos, fundo em 1951 a revista Nueva Visión, uma publicação que teve, naquela época, uma influência considerável na Argentina, e da qual durante quatro anos fui diretor (MALDONADO, 2010: 109-10).

\section{2 nueva visión - revista de cultura visual (1951-1957)}

Em 1951, dois importantes empreendimentos seriam colocados em prática por Tomás Maldonado, Alfredo Hlito e Carlos Méndez Mosquera: a criação de axis organización de publicidad integral, primeiro estúdio argentino de desenho industrial e comunicação visual, e a fundação da revista nueva visión. Ambos, assim como outros grupos argentinos como oam (organización de arquitectura moderna) e harpa, eram escritos com "fanático e estrito minusculismo tipográfico", segundo conta Méndez Mosquera (1997:10).

Apesar de ter desenvolvido alguns projetos relevantes, a proposta de comunicação visual moderna do estúdio não encontrou acolhimento no ambiente argentino e encerrou suas atividades em 1953 (DEAMBROSIS, 2011). nueva visión, entretanto, seria publicada, não sem esforço, até 1957, alcançando nove números.

A edição inaugural da revista, dirigida por Maldonado, foi produzida em sua casa, na avenida Santa Fé, e publicada - com 20 páginas impressas em papel couché brilho - em dezembro de 1951. Méndez Mosquera, amigo de Maldonado desde 1947, quando ainda era estudante do curso de arquitetura da Universidade de Buenos Aires, assumiu a secretaria da publicação, e Hlito, colega na Academia de Belas Artes, foi o responsável pela diagramação.

A revista surge no vácuo das experiências de publicações como Ciclo e Boletín del Cea, refletindo ainda a interação, no circuito cultural portenho, de jovens arquitetos modernos e de artistas concretos. Desde seu subtítulo - "revista de cultura visual" - expressava um projeto

Anais [Oral] do $7^{\circ}$ Congresso Internacional de Design da Informação | CIDI 2015

Proceedings [Oral] of the 7th Information Design International Conference | IDIC 2015 
editorial amplo o suficiente para debater questões relacionadas às manifestações artísticas de vanguarda, passando pela arte concreta, pela arquitetura e pelo desenho industrial. De acordo com Lucena (2011), o nome da publicação remete ao termo cunhado por Moholy-Nagy e que diz respeito à invenção de novos objetos artísticos e de relações entre o homem, seus sentidos, suas percepções e o mundo que o cerca. Inscrita a partir desses referentes, segundo Devalle, em nueva visión:

[...] encontramos uma nova concepção do espaço, uma problematização daquilo que hoje consideraríamos linguagem visual (ali chamada de "cultura visual") e a inquietante pergunta pela forma transformada em sentido. Por esses motivos, a consideramos o primeiro discurso habilitante do Design na Argentina (DEVALLE, 2009: 252).

Dentre as empresas que prestaram apoio à revista como anunciantes, estavam oficinas e lojas de mobiliário moderno (aim, Silla Jannello, Atelier Decoraciones, Interieur, Comte, harpa), fábricas de material de construção (Ameriplastes, Polledo), de luminárias (gamma, llum, Dobila), de máquinas de lavar (Kenig, Cazzaniga y Cía) e de gravadores de som (Apel). Também anunciaram em nueva visión companhias de seguros, galerias de arte, gráficas, óticas e fabricantes de bebidas. Além desses, livrarias, editoras, revistas culturais argentinas e estrangeiras - inclusive a brasileira Habitat, então dirigida por Lina Bo Bardi - e a própria axis e editorial nueva visión. Os layouts da maioria dos anúncios seguiam a orientação minimalista, geométrica e eram essencialmente tipográficos (com destaque para as fontes não serifadas), o que conferia harmonia visual entre o conteúdo editorial e comercial da publicação.

Os representantes da revista em outras localidades, por sua vez, refletiam as amizades e contatos mantidos por Maldonado dentro e fora da Argentina: César Janello em Mendoza, Ricardo Muratorio Posse em Tucumán, Lanfranco Bombelli Tiravanti em Paris, Max Huber em Milão, Hans Platschek em Montevidéu e o artista gráfico Tomás Santa Rosa no Rio de Janeiro.

Figura 5: Alguns dos anunciantes de nueva visión. Fonte: CeDInCl. Reprodução: P. Amorim.

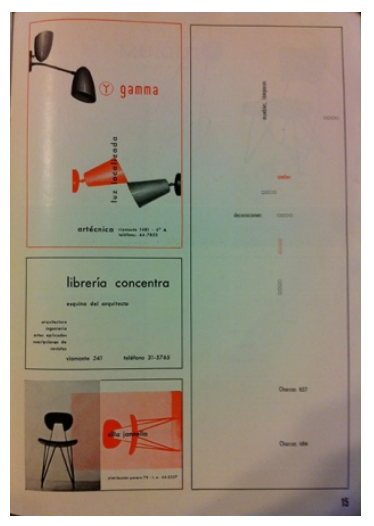

Figura 6: Páginas iniciais do artigo Actualidad y porvenir del arte concreto. Revista nueva visión, № 1 . Fonte: CeDInCl. Reprodução: P. Amorim.

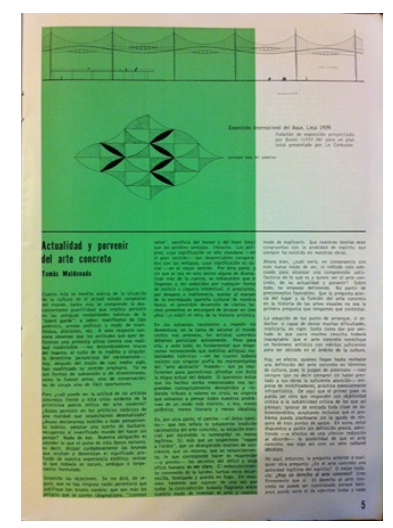

\section{A forma gráfica de nueva visión}

A capa do primeiro número de nueva visión, concebida por Alfredo Hlito, era o testemunho gráfico da alma da publicação. Sobriedade e racionalidade davam as coordenadas para a articulação de áreas retangulares nas cores branco, preto e verde, as quais abarcavam as informações de texto, compostas em tipos condensados e sem serifas, seguindo o ordenamento de eixos verticais. "A gráfica da revista, ligeiramente expressionista, tem a personalidade de Alfredo Hlito e meus balbuceios como designer gráfico", comentou certa vez Méndez Mosquera (1997: 12). 
Figura 7: Revista nueva visión, $N^{\circ}$ 1. Fonte: CeDInCl.

Reprodução: P. Amorim.

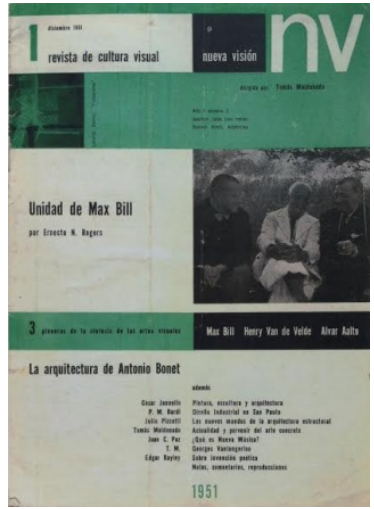

Figura 8: Revista nueva visión, $\mathrm{N}^{\circ}$ 2/3. Fonte: CeDInCl. Reprodução: P. Amorim.

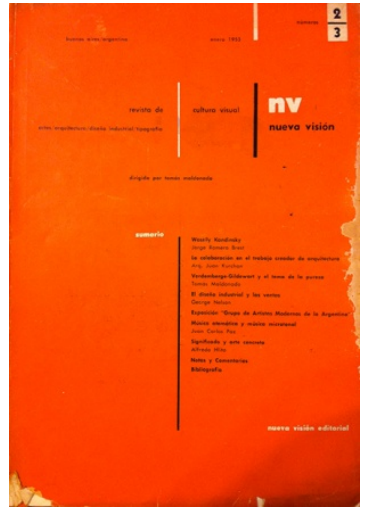

Figura 9: Revista Moderne Schweizer Architektur, $\mathrm{N}^{\circ} 1,1940$. Fonte: http://www.stoutbooks.com/cgibin/stoutbooks.cgi/66597.

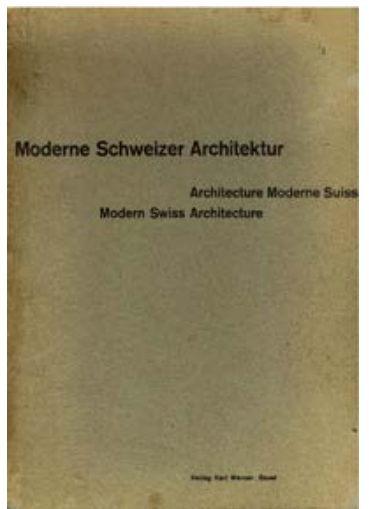

A foto de uma conversa entre Max Bill, Henri van de Velde e Alvar Aalto aparece em destaque, nomeados pelo periódico como os "três pioneiros da síntese das artes visuais". Ressaltam-se ainda chamadas para textos sobre Max Bill e o arquiteto Antoni Bonet, além dos escritos dos colaboradores César Jannello, Pietro Maria Bardi, Júlio Pizzelli, Juan C. Paz, Edgar Bayley e do próprio Tomás Maldonado. No topo do layout, desponta um dos fotogramas do brasileiro Geraldo de Barros.

O "propósito ambicioso" de nueva visión, de "propiciar a síntese de todas as artes visuais em um sentido de objetividade e funcionalidade" - como proclamado em seu primeiro editorial transparece, portanto, nesta pauta multifária. Nela constaram menções a Walter Gropius, a Moholy-Nagy, à música dodecafônica de Schöenberg e ao artista neoplasticista Georges Vantongerloo. Arquitetura, pintura, desenho industrial e música de viés vanguardista ganhavam um espaço comum para divulgação e debate, pondo em prática a função que a revista escolheu para si: " $n v$ é, ao mesmo tempo, a revista dos desenhistas industriais, dos engenheiros, dos cineastas, dos artistas gráficos, de todos aqueles que, direta ou indiretamente, ajudam na tarefa de construir uma nova cultura visual" (NUEVA visión,1951: 2).

A edição seguinte de nueva visión, números $2 / 3$, seria lançada pouco mais de um ano depois, em janeiro de 1953, dessa vez com 40 páginas, o que constituiria a média da publicação para as demais edições. Trazia agora, complementando a denominação "revista de cultura visual", um subtítulo mais específico "artes/arquitectura/diseño industrialltipografía". A redação passava a funcionar num pequeno prédio, hoje demolido, na rua Cerrito, 1371, em Buenos Aires, espaço que funcionava como laboratório, showroom e sala de reuniões. Além disso, novos membros haviam sido incorporados: os arquitetos Juan Borthagaray, Francisco Bullrich, Jorge Goldemberg e Jorge Grisetti, todos integrantes da oam. Méndez Mosquera, recém-casado, desvinculou-se para dedicar-se a atividades de melhor remuneração, embora mantivesse contato com o grupo (DEAMBROSIS, 2011). O nome de Alfredo Hlito não aparece no expediente deste número, retornando na quinta edição.

O fato é que este número duplo de nueva visión foi alvo de uma reforma gráfica desencadeada por uma crítica de Max Bill, feita por carta a Maldonado, datada de janeiro de 1952: " $n v$ me provocou um grande prazer. é a revista que faltava. o que não gosto é a paginação: muito complicada, muito 'arte decorativa' e muito pouco elementar" (GARCÍA, 2011: 146). Em atenção ao "ascetismo gráfico maxbilliano", como definiu Méndez Mosquera, o novo projeto de capa de nueva visión excluiu o uso de imagens e inspirou-se em publicações suíças como Moderne Schweizer Architektur, do próprio Bill, Allianz, Konkrete Kunst e outras. 
Sobre um fundo de cor uniforme, neste caso laranja, finas faixas verticais pretas e brancas conduziam o alinhamento das sintéticas informações verbais do cabeçalho e do sumário, padrão que se repetiria nas edições subsequentes. Toda a revista passou a ser composta com a família tipográfica Futura, à exceção de alguns anúncios.

\section{Summa - revista de arquitectura, tecnología y diseño (1963-1969)}

Summa foi lançada em abril de 1963. A capa em fundo branco trazia o nome da publicação impresso na vertical em Helvetica Bold, ocupando quase toda a altura do papel. No canto superior direito, o número 1, indicativo da edição, e no inferior, o subtítulo: Revista de arquitectura, tecnología y diseño, composto em Futura. Esse layout de capa, tributário do Estilo Tipográfico Internacional, perduraria até o nono número do periódico, com variação apenas na cor das informações de texto. Diante de tal contenção e racionalidade gráfica, seus leitores acabariam referindo-se à revista como "La Blanca", segundo Lala Méndez Mosquera (2013), diretora da publicação por 26 anos.

Figura 9: Revista Summa, № 1. Fonte: SCA. Reprodução: P. Amorim.

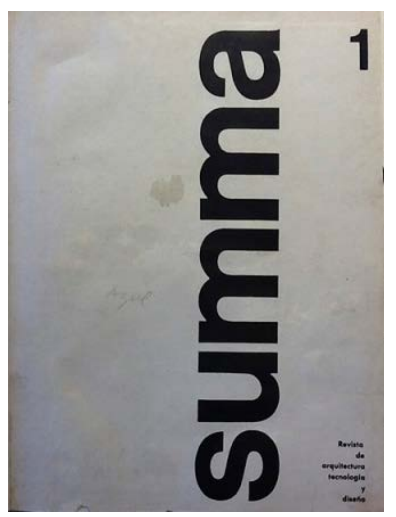

A chegada de Summa ocorreu num momento em que o desenho industrial na Argentina já havia dado passos importantes rumo à institucionalização acadêmica e classista, bem como à ampliação da prática profissional tanto nos quadros da indústria quanto da publicidade.

Em 1953, por exemplo, o arquiteto Carlos Méndez Mosquera - que havia integrado a revista nueva visión e o estúdio axis ao lado de Tomás Maldonado e Alfredo Hlito - funda Cícero Publicidad. Nesse mesmo ano, os arquitetos Jorge Ferrari Hardoy, Eduardo Aubone, José Rey Pastor e Leonardo Aizenberg criam o estúdio harpa, especializado em mobiliário contemporâneo. Méndez Mosquera, após retornar de sua primeira viagem à Europa, incorpora-se à harpa, e juntos fundam ediciones infinito, em 1954. A editora exerceria grande importância na disseminação do pensamento moderno sobre arquitetura e desenho industrial em língua espanhola naquele período.

Como parte do processo de renovação acadêmica no país, a disciplina Visión, elaborada a partir dos ensinamentos de Moholy-Nagy na Bauhaus e na Escola de Chicago, é introduzida no curso de arquitetura da Universidade de Buenos Aires (UBA) em 1956. Também neste ano, é fundado o Instituto Nacional de Tecnología Industrial (INTI), o qual abriria caminho para o surgimento do Centro de Investigación de Diseño Industrial (CIDI), em 1962. O Instituto Torcuato Di Tella, que contaria com um departamento interno de comunicação visual, surge em 1958.

Nesse mesmo ano, é criado o departamento de desenho industrial na Universidad Nacional de Cuyo (UNCuyo). Iniciativa reproduzida em 1960 na Universidad Nacional de La 
Plata (UNLP), onde o curso dividia-se nas habilitações desenho industrial e comunicação visual. Mais adiante, em 1963, a Universidad del Litoral também promove formação nesta área. A Asociación Disenãdores Industriales Argentinos (ADIA) é fundada em 1962, sendo reconhecida como membro do ICSID em 1965, título que já havia sido conferido ao INTI e ao CIDI. Em função disso, a Argentina torna-se o primeiro país latino-americano internacionalmente reconhecido como produtor de design (CIDI, 1969).

A consolidação do desenho industrial na Argentina estava, portanto, profundamente relacionada a articulações como as acima mencionadas. Favorecidas, segundo De Ponti \& Gaudio (2008), pela política econômica de substituição de importações e pela expansão da indústria local, que tinha entre seus principais representantes o grupo SIAM Di Tella e ATMA.

Internacionalmente, Tomás Maldonado operava como um dos principais elos de intercâmbio entre a Europa e a Argentina, com reflexos em países vizinhos como o Brasil. Isso se dava por conta da posição que ocupava no corpo docente e diretivo da Hochschule für Gestaltung (HfG-UIm), da colaboração com a Olivetti e de sua atuação no ICSID, bem como às relações de amizade mantidas com ex-colegas da revista nueva visión e os contatos com o CIDI.

Assim, levando em conta todo esse cenário de interconexões, verifica-se que Summa será concebida num contexto bastante diferente daquele no qual emergiu a desbravadora nueva visión doze anos atrás. O desenho industrial, como afirmava Méndez Mosquera no editorial do segundo número de Summa, encontrava-se num período mais maduro, e a própria revista, de certo modo, seria uma consequência dessa evolução.

\section{A arquitetura tipográfica de Summa}

Carlos Méndez Mosquera e sua então esposa, Lala Méndez Mosquera, ambos arquitetos formados pela UBA, eram entusiastas da tipografia. O próprio nome da agência que fundaram, Cícero Publicidad, homenageava a unidade de medida tipográfica cícero, do sistema criado por François-Ambroise Didot, no final do século XVIII. De acordo com Lala, os limitados recursos gráficos disponíveis em Buenos Aires nos anos 1950 eram um desafio à prática de uma comunicação visual moderna. Caminho tortuoso que, no entanto, acabou por contribuir para o surgimento de Summa mais adiante:

Nós que estávamos em Cícero Publicidad queríamos fazer os anúncios com tipografia etrusca [sem serifa]. Tempos depois, encontramos uma pequena gráfica que tinha os tipos de uma etrusca, mas as recortávamos de Bauen+Wohnen [revista alemã de arquitetura], letra por letra, e montávamos [o layout]... Fazíamos isso para que a tipografia estivesse atualizada, como manda o design gráfico, muito estrito. Usávamos a etrusca ou Akzidenz Grotesk, Bodoni, Garamond, que são uma maravilha, todo o estudo por trás de cada tipografia dessas é uma maravilha. Tudo isso levou a que eu me dedicasse à parte gráfica da agência. Trabalhamos juntos também, mas ele [Carlos] dedicou-se a dirigir a empresa, que há medida que o tempo passava ia bastante bem. Então chegou o dia em que, dez anos depois de trabalhar em Cícero, apareceu Summa. E depois do primeiro número, foi como um acontecimento que deixou uma marca na história do diseño gráfico aqui (MÉNDEZ MOSQUERA, 2013).

No momento em que a revista nasce, Carlos Méndez Mosquera estava envolvido com as atividades publicitária e editorial em Cícero e Ediciones Infinito, além da prática docente nas faculdades de arquitetura da Universidad del Litoral e da UBA. Nessas instituições, ministrou aulas de tipografia e design gráfico na matéria Visión, a qual concebeu em conjunto com os colegas Gastón Breyer, César Janello, José Alberto Le Pera, Samuel Oliver e Rafael Onetto. Em 1963, se tornaria diretor de Agens, empresa de publicidade pertencente ao grupo siam Di Tella.

Engajado de tal modo com o tema e tendo em vista os pouquíssimos periódicos voltados à arquitetura então disponíveis no país, Carlos Méndez Mosquera decide fundar a revista Summa, com sede na rua Lavalle, número 543, na capital federal. Integraram a redação José Alberto Le Pera, José M. Marchetti, Ernesto L. Milsztejn e Lala, sua esposa, responsável pela diagramação da revista com a assistência de Sara Torossian.

Anais [Oral] do $7^{\circ}$ Congresso Internacional de Design da Informação | CIDI 2015

Proceedings [Oral] of the 7th Information Design International Conference | IDIC 2015 
Com formato fechado $23 \mathrm{~cm} \times 30 \mathrm{~cm}$, os quinze números iniciais de Summa foram impressos pela gráfica Parada Obiol. A primeira edição saiu com 172 páginas. Esse número flutuaria, chegando a uma média de 90 páginas entre as edições 11 e 15 . No miolo, em preto e branco, composto na fonte Futura em papel couché brilho, utilizava-se um grid de duas colunas para matérias e artigos, com variação de quatro colunas para seções de notas curtas como Noticias, Cartas a la redacción, Noticias biográficas, Comentarios bibliograficos e Revista de revistas. Essas duas últimas seções traziam a resenha de livros recém-lançados e revistas internacionais especializados em arquitetura e design. Nos três primeiros números, Summa publicou resumos em inglês e francês de seus principais artigos.

Figura 10: Artigo Diseño industrial, Argentina 1963. Summa, № 2. Fonte: arquivo pessoal. Reprodução: P. Amorim.

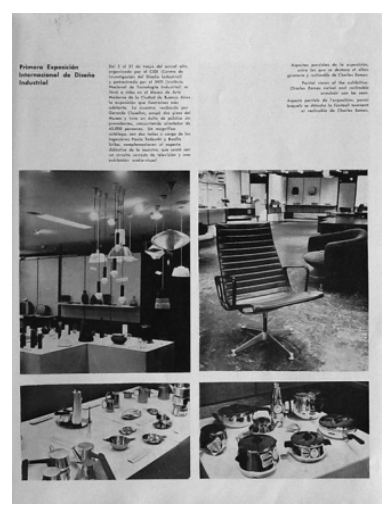

Figura 11: Revista UIm, № 6. Fonte: Biblioteca FADU UBA.

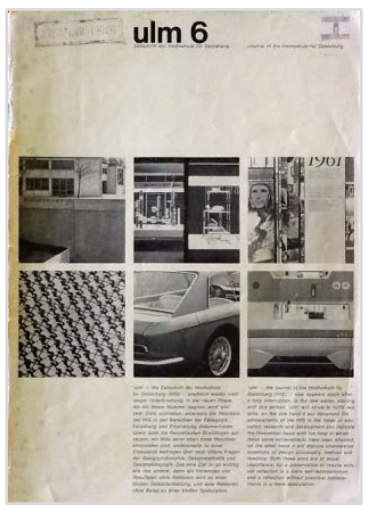

A revista apresentava e criticava projetos arquitetônicos e urbanísticos, ilustrados por plantas e fotografias das edificações e de seus interiores, fossem eles residenciais, comerciais ou industriais. Os conteúdos específicos de desenho industrial, embora ocupassem menos espaço na publicação, incluíam desde artigos teóricos, a apresentação de peças de mobiliário de designers argentinos, passando por projetos na área de comunicação visual e publicidade, até descrições técnicas de objetos de fabricação industrial, como um aparelho de som ou uma máquina de cortar fiambre. Alguns textos eram republicações de revistas estrangeiras, dentre elas UIm, periódico da HfG-Ulm editado por Maldonado. Características visuais do projeto gráfico racionalista da revista alemã também podiam ser observados em Summa, tendência inclusive bastante comum entre as revistas desse segmento naquela época, como já comentado.

Vale destacar que as diversas seções de notas de Summa divulgaram intensamente eventos como seminários, exposições, concursos, cursos e premiações, nacionais e estrangeiros, com especial atenção para as atividades promovidas pelo CIDI na Argentina, bem como edições da Conferência de Design de Aspen e os congressos do ICSID, então principais eventos internacionais na área.

Dentre as empresas que anunciaram em Summa constavam fábricas de materiais de construção (Acindar, Iggam, Hulytego, Kocourek, Bratina, Dutecnica, Cita, Fiplasto, Flamia, Termeco, Magnus, Sima, Modernfold, Phonex, Castelar, etc), de automóveis e autopeças (Kaiser, Fate), de aparelhos eletrônicos (atma, Aurora, siam, Olivetti Argentina), de lojas de decoração (Six, Herman Miller, harpa, Interieur Forma, Exedra, Modulor, Droll, Norhaus), de companhia de seguros, de papelarias e lojas de desenho técnico, periódicos, agências de publicidade, além de ediciones infinito e editorial nueva visión, entre outros. Também em seus layouts costumavam ser empregados elementos típicos do design gráfico suíço, como as formas geométricas puras, a organização espacial assimétrica e a tipografia sem serifa, com foco na clareza visual (MEGGS, 2009). 
Figuras 12, 13, 14: Alguns dos anunciantes de Summa: Herman Miller, harpa e SIAM. Fonte: coleção particular. Reprodução: P. Amorim.
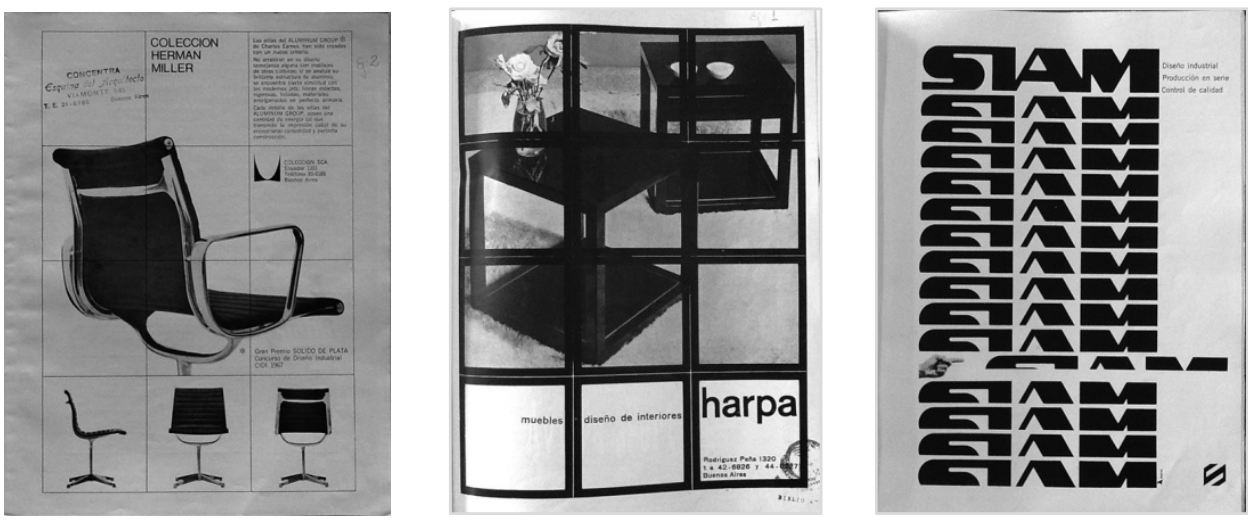

De acordo com Lala, a maioria dos anunciantes eram clientes de Cícero Publicidad, o que ajudava, em certa medida, a viabilizar o projeto da revista: "Carlos tentava convencer a clientela a apoiar a arquitetura, o design, a gráfica, a cultura" (MÉNDEZ MOSQUERA, 2013).

Mas as dificuldades em manter uma publicação logo se impuseram, e Summa não conseguiu, de início, circular com periodicidade definida, produzindo edições em intervalos irregulares.

Segundo Lala,

[Summa] começou a competir com o trabalho, porque fazíamos tudo depois do expediente ou durante, inclusive. Em Cícero, eram feitos todos os anúncios, conteúdos, toda a diagramação. Mas em dois anos saíram apenas quatro números. $\mathrm{E}$ depois do primeiro, o segundo número foi mais difícil, o terceiro, muito mais difícil e o quarto foi feito quase sem Carlos, e Le Pera ia colaborando menos, pois não tinha muito tempo (MÉNDEZ MOSQUERA, 2013).

A quinta edição de Summa, publicada em julho de 1966, foi, portanto, decisiva para a continuidade do projeto. Neste momento, Lala torna-se diretora de redação e Carlos passa à função de editor:

$\mathrm{Na}$ [número] cinco, fui com a revista para outro escritório, na [rua] Viamonte com San Martin fisicamente à parte. Porque [Summa] já vinha languidescendo, já estava por desaparecer. Tinha que pegá-la ou deixá-la morrer. Então, decidi levá-la e comecei a trabalhar com [Jorge] Grisetti e também Leonardo Aizenberg, um dos membros de harpa. Foi uma mudança importante, pois era como um resgate. E então teve início um longo e difícil caminho (MÉNDEZ MOSQUERA, 2013.

Figuras 15 e 16: Capas das edições 5 e 15 de Summa.

Fonte: coleção particular. Reprodução: P. Amorim.

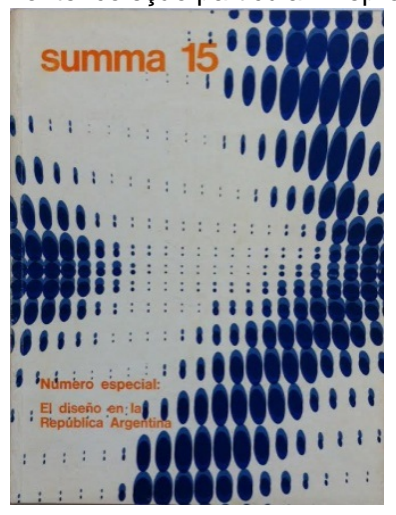

Anais [Oral] do $7^{\circ}$ Congresso Internacional de Design da Informação | CIDI 2015

Proceedings [Oral] of the 7th Information Design International Conference | IDIC 2015 
De acordo com Lala, em paralelo à Summa surgiram importantes lojas de decoração e de iluminação em Buenos Aires, várias delas de propriedade de amigos, os quais se alinhavam numa atitude moderna frente à arquitetura e o desenho industrial e que iam crescendo juntos, a despeito dos obstáculos.

Passamos por tempos difíceis também na parte econômica da revista, porque ela nunca durou muito autossustentada. Muitas vezes, isso era trabalho meu, fui buscar aportes que por sorte, suponho, se reuniam. Então nós íamos seguindo, e cada vez mais os arquitetos, éramos todos muito jovens, iam crescendo. A conexão com todos eles se mantinha. Demos espaço aos arquitetos para mostrarem suas coisas em Summa, e eles vinham com seus rolos debaixo do braço (MÉNDEZ MOSQUERA, 2013.

Apesar das adversidades, Summa circulou por 29 anos. Suas quinze primeiras edições foram publicadas com periodicidade instável. A partir de 1969, com o $16^{\circ}$ número, a revista tornase mensal, chegando a um total de 300 edições, em 1992. Também foram lançados títulos simultâneos, como Summarios, Summa Universitaria, Summa Colección Temática e Cuadernos Summa-Nueva Visión, os quais colaboraram, juntamente com a revista principal, para a difusão e a compreensão da arquitetura e do desenho industrial na Argentina e na América Latina. Em 1993, contudo, sem fôlego financeiro, Summa seria descontinuada.

\section{Considerações finais}

Após esse sucinto panorama da trajetória de nueva visión e Summa, observa-se que, em sintonia com o interesse em divulgar e discutir temas emergentes nos anos 1950 e 1960, como a arte concreta e o desenho industrial, tais revistas buscaram refletir em suas capas e projetos gráficos as tendências estéticas associadas a esses temas. Articulando componentes visuais da página impressa como tipos sem serifa, grids matemáticos, organização assimétrica e elementos gráficos como barras, fios e boxes opacos ou reticulados, ambos os periódicos são exemplos de publicações nas quais os conteúdos editorial e comercial serviram de matéria-prima para a experimentação gráfica vanguardista. Mesmo a despeito das limitadas condições técnicas de impressão relatadas pelos integrantes dessas revistas, nueva visión e Summa conseguiram colocar-se como interlocutoras no diálogo internacional que naquelas duas décadas perseguiu obstinadamente o tão almejado ideal da boa forma.

\section{Referências}

CIDI Centro de Investigación de Diseño Industrial. 1969. Summa, Buenos Aires, n. 15.

DE PONTI, J.; GAUDIO, A. 2008. Argentina 1940-1983. In: FERNÁNDEZ, S; BONSIEPE, G. Historia del diseño en América Latina y el Caribe: Industrialización y comunicación visual para la autonomía. São Paulo: Blucher.

DEAMBROSIS, F. 2011. Nuevas visiones: revistas, editoriales, arquitectura y arte en la Argentina. Buenos Aires: Infinito.

DEVALLE, V. 2006. Un nuevo planteo conceptual sobre la tipografia. Maldonado y la revista nueva visión. Questión, Buenos Aires, vol.1, n. 11. < http://perio.unlp.edu.ar/ojs/index.php/question/article/viewArticle/221>, 17/04/2011.

DEVALLE, V. 2009. La travessia de la forma. Emergencia y consolidación del diseño gráfico (1948-1984). Buenos Aires: Paidós.

LUCENA, D. 2011. Arte concreto y Nueva Visión: una lectura en clave política. Aurora, n.10. $<w w w . p u c s p . b r / r e v i s t a a u r o r a>, 11 / 01 / 2012$.

GARCÍA, M. 2011. El arte abstracto: intercâmbios culturales entre Argentina y Brasil. Buenos Aires: Siglo Veinteuno Editores.

Anais [Oral] do $7^{\circ}$ Congresso Internacional de Design da Informação | CIDI 2015

Proceedings [Oral] of the 7th Information Design International Conference | IDIC 2015 
MALDONADO, Tomás. 1997. Escritos Preulmianos. Buenos Aires: Ediciones Infinito.

. 2010. Tomás Maldonado: in conversation with = en conversación con María Amália García. New York: Fundación Cisneros.

MANIFIESTO Invencionista. 1997. In: MALDONADO, Tomás. Escritos Preulmianos. Buenos Aires: Ediciones Infinito.

MEGGS, P. 2009. História do design gráfico. São Paulo: Cosac Naify.

MÉNDEZ MOSQUERA, C. 1997. Introducción. In: MALDONADO, Tomás. Escritos Preulmianos. Buenos Aires: Ediciones Infinito.

1969. Veinte años de diseño gráfico en la República Argentina. Summa, Buenos Aires, n.15.

MÉNDEZ MOSQUERA, L. 2013. Entrevista concedida a este trabalho.

NUEVA visión. 1951. Buenos Aires, n.1.

PERAZZO, N. 1997. Tomás Maldonado y los orígenes de la vanguardia argentina. In:

MALDONADO, Tomás. Escritos Preulmianos. Buenos Aires: Ediciones Infinito.

\section{Sobre as autoras}

Patricia Amorim, Doutora, ESPM-SP, Brasil <pat.amorim@gmail.com>

Virginia Cavalcanti, Doutora, UFPE, Brasil <cavalcanti.virginia@gmail.com> 